\title{
Article \\ Conductive Biomass Films Containing Graphene Oxide and Cationic Cellulose Nanofibers for Electric-Heating Applications
}

\author{
Shanqing Liang *, Huicong Wang and Xin Tao
}

check for updates

Citation: Liang, S.; Wang, H.; Tao, X.

Conductive Biomass Films

Containing Graphene Oxide and Cationic Cellulose Nanofibers for Electric-Heating Applications. Nanomaterials 2021, 11, 1187. https:// doi.org/10.3390/nano11051187

Academic Editor: Hirotaka Koga

Received: 14 April 2021

Accepted: 22 April 2021

Published: 30 April 2021

Publisher's Note: MDPI stays neutral with regard to jurisdictional claims in published maps and institutional affiliations.

Copyright: (c) 2021 by the authors. Licensee MDPI, Basel, Switzerland. This article is an open access article distributed under the terms and conditions of the Creative Commons Attribution (CC BY) license (https:// creativecommons.org/licenses/by/ $4.0 /)$.
Research Institute of Wood Industry, Chinese Academy of Forestry, Beijing 100091, China; whchong95@163.com (H.W.); taushin1994@163.com (X.T.)

* Correspondence: liangsq@caf.ac.cn; Tel.: +86-10-62889241

Abstract: A low-voltage biomass matrix and flexible electric-heating composite with graphene oxide (GO) and cationic cellulose nanofiber (CCNF) were fabricated by ultrasonic dispersion and suction filtration. The main results show that the tensile strength and strain of the films decreased with an increase in the GO content, but the thermal stability increased. The GO/CCNF film underwent rapid thermal decomposition at $250-350^{\circ} \mathrm{C}$, and the maximum degradation temperature was higher by $19^{\circ} \mathrm{C}$ compared to that of the pure CCNF film. It was found that the electrical conductivity increased from 0.013 to $2.96 \mathrm{~S} / \mathrm{cm}$ with an increase in the GO content from 20 to $60 \mathrm{wt} \%$, resulting in an increase in the power density from 122 to $2456 \mathrm{~W} / \mathrm{m}^{2}$. The films could rapidly attain the temperature within $50 \mathrm{~s}$, and the heat transferred by radiation and convection was $21.62 \mathrm{~mW} /{ }^{\circ} \mathrm{C}$, thereby exhibiting excellent electric heating response. Moreover, the film demonstrated a stable electric-heating cycle after a $12.5 \mathrm{~h}$ cycling test and meets the requirements of low-temperature electric heating products under the $36 \mathrm{~V}$ electric safety limit, which expands the potential applications of biomass-derived cellulose nanofibers.

Keywords: graphene; cationic cellulose nanofiber; conductivity; electric-heating performance; power density

\section{Introduction}

Electric-heating composites can convert electrical energy into heat energy in a controlled manner and have been widely used in many fields [1-3]. However, traditional electric-heating composites cannot meet the needs of the rapidly developed electrothermal products, owing to their disadvantages of low heat-transfer efficiency, complex preparation techniques, and non-flexibility. Currently, carbon materials are the preferred conductive materials for electric-heating composites because of their light weight, low voltage, oxidation resistance, rapid electric-heating response, and high heat-transfer efficiency. Carbon materials such as graphene, carbon nanotubes, and carbon fibers [4] have been used to synthesize electric-heating composites with applications in smart wear [5-7], heating and healthy clothing [8], deicing products [9], and electric-heating coatings [10]. Therefore, the study of carbon-based electric heating composites has become an interesting research direction. Some investigators have carried out extensive and in-depth studies on preparation methods, the selection of matrices, and functionalization.

Graphene is used to prepare low-voltage and high-efficiency electric-heating composites owing to its excellent electrical conductivity, thermal conductivity, high specific surface area, and mechanical properties. The preparation methods mainly include suction filtration, wet spinning, chemical vapor deposition (CVD), and spin coating [11,12]. For example, using polyethylene terephthalate (PET) as the matrix, graphene electrothermal films have been prepared by the CVD method, in which graphene was deposited on the surface of a PET substrate. The square resistance of the films was $159 \Omega$, and the maximum temperature was in the range $33-139{ }^{\circ} \mathrm{C}$ at a load of 5-30 V, and they exhibited a fast electric-heating response [13]. Similarly, good results were obtained for graphene-based 
electric heating films prepared by the wet spinning method. The steady-state temperatures of the films were in the range $33-177^{\circ} \mathrm{C}$ after 2 min of loading voltage [14]. In addition, spin-coating and spraying methods have been used to prepare electric-heating films with quartz or flexible polyimide as the substrate. Furthermore, a fabric electric-heating material has been fabricated by the spraying method, and its steady-state temperature reached $162.6^{\circ} \mathrm{C}$ at a load of $10 \mathrm{~V}$, which proves that the graphene-based electric-heating composite has a high electric-heating efficiency [15].

In addition to the use of resin, quartz, and fabric as substrates, environmentally friendly cellulose (with advantages such as renewability, biocompatibility, non-toxicity, hydrogen-bonding capacity, sustainability) has attracted the attention of researchers, and the electrical, electrochemical, and electromagnetic characteristics of biomass-based composite films have been investigated [16-19]. Recently, research groups have reported the use of graphene and carbon nanotubes to prepare degradable electric heating composites by their impregnation on cellulose paper or mixing with cellulose. The results demonstrated several advantages including high electrical conductivity, rapid electrothermal effect, and low energy consumption [20,21]. However, nanocellulose-based films or gels prepared using cellulose microfibrils, microcrystalline cellulose, cellulose nanocrystals, cellulose nanofibrils, and bacterial cellulose show different electrical conductivities, which directly affect the electric properties of the composites [22,23], and cationic nanocellulose and anionic GO have been investigated and shown to be beneficial to the dispersion and reinforcement of composite materials [24-26]. It is very important to study the properties of electrothermal composites prepared from various types of nanocellulose, to obtain more reliable results and further promote the practical applications of nanocellulose-based electric-heating composites.

In this paper, we present an eco-friendly electric-heating composite of GO and CCNF synthesized via a simple ultrasonic dispersion and vacuum filtration method. The effects of different GO contents on the mechanical properties, thermal stabilities, and electricheating performances of the GO/CCNF films were characterized via micromechanical testing, scanning electron microscopy (SEM), electrothermal performance testing, and Raman spectroscopy. The electric-heating response and electric-to-radiant power transfer efficiency were analyzed thoroughly to provide a reference for the application of biomassderived nanocellulose-based electric-heating composites.

\section{Materials and Methods}

\subsection{Materials}

An aqueous dispersion of graphene oxide (TNWPRGO), with a GO content of $1.30 \mathrm{wt} \%$ (dispersant content $0.3 \mathrm{wt} \%$ ), purity $>98 \mathrm{wt} \%$, thickness of $0.5-3.7 \mathrm{~nm}$, median diameter $\mathrm{D}(50)$ of $4-6 \mu \mathrm{m}$, number of layers $<10$, and surface area of $500-700 \mathrm{~m}^{2} / \mathrm{g}$, was purchased from Chengdu Organic Chemistry Co., Ltd. (Chengdu, China), Chinese Academy of Sciences. Aqueous cationic cellulose nanofibers were procured from Tianjin Woodelf Biotechnology Co., Ltd. (Tianjin, China), with a CCNF content of $1.17 \mathrm{wt} \%$, diameter of $10-15 \mathrm{~nm}$, length of 1-5 $\mathrm{m}$. Anhydrous ethanol (purity 99.7\%) was purchased from SigmaAldrich (St. Luis, MO, USA). Conductive silver glue, copper wire (diameter $0.12 \mathrm{~mm}$ ), polytetrafluoroethylene (PTFE) membrane (hydrophilic type, diameter $110 \mathrm{~mm}$, and pore size $0.22 \mu \mathrm{m}$.) were obtained from a market. All materials and chemicals were used as received, without further purification.

\subsection{Preparation of GO/CCNF Films}

GO/CCNF films with different GO contents were prepared sequentially. Initially, GO (mass ratios: 1, 5, 10, 20, 30, 40, 50, and 60\%) and CCNF aqueous dispersions were mixed in a $100 \mathrm{~mL}$ glass beaker. The solid content of the mixed GO and CCNF was $0.58 \mathrm{~g}$. Then, $50 \mathrm{~g}$ distilled water was added and the mixture was subjected to sonication using an ultrasonic generator at $600 \mathrm{~W}$ for $5 \mathrm{~min}$ (water bath) followed by magnetic stirring for $30 \mathrm{~min}(1500 \mathrm{rpm})$. The mixture was quickly poured into a Buchner funnel with a 
polytetrafluoroethylene filter and filtered via vacuum filtration for $5 \mathrm{~h}$. The films were placed with the polytetrafluoroethylene filter and dried in a vacuum oven at $60^{\circ} \mathrm{C}$ for $2 \mathrm{~h}$. Finally, the films were mechanically peeled off from the polytetrafluoroethylene filter by immersion in absolute ethyl alcohol for $2 \mathrm{~min}$ and were dried at room temperature (Figure 1).

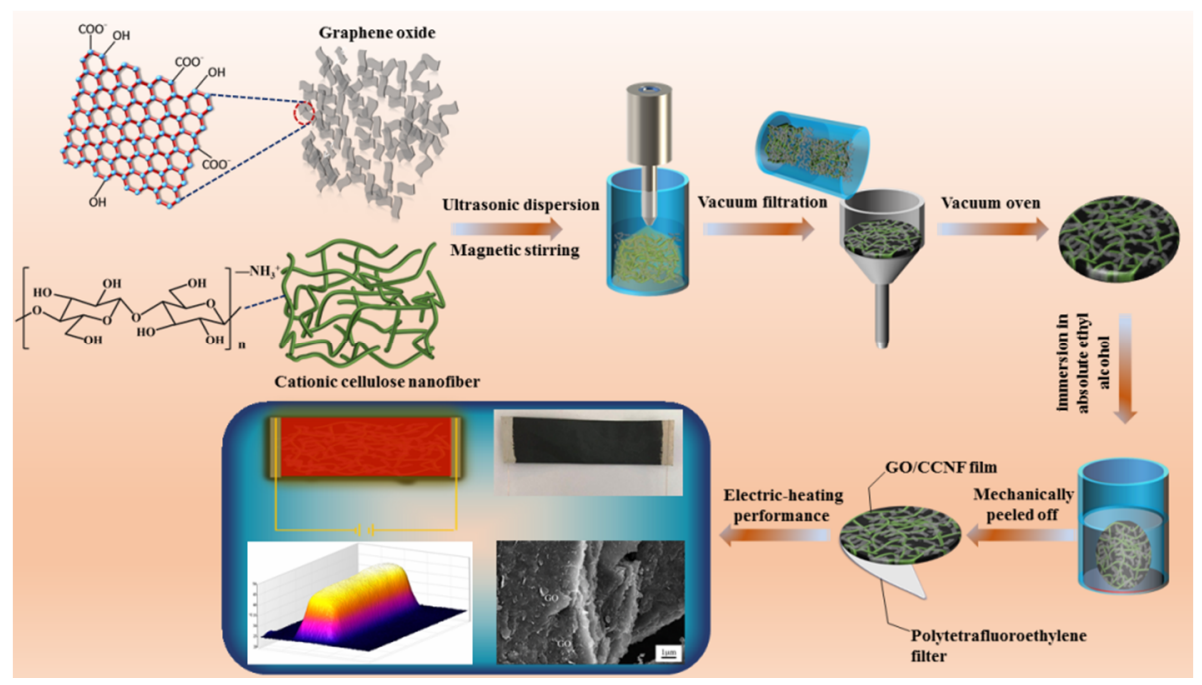

Figure 1. A schematic for preparing method and testing electric-heating performance of GO/CCNF composite films.

\subsection{Characterization}

The GO/CCNF films were characterized via mechanical testing, SEM, and thermogravimetric analysis (TG and DTG). Samples of pure CCNF, GO/CCNF-20\%, GO/CCNF$40 \%$, and GO/CCNF- $60 \%$ of $60 \mathrm{~mm} \times 2 \mathrm{~mm}$ each were prepared and placed at room temperature for 1 week. Subsequently, their stress-strain properties were tested at a tensile speed of $0.5 \mathrm{~mm} / \mathrm{min}$ (Shimadzu Autograph AGS-X, Shimadzu, Tokyo, Japan). The microstructures of the films were observed using a scanning electron microscope (Hitachi S4800, Hitachi, Tokyo, Japan) at a voltage of $10 \mathrm{kV}$. Further, the thermal stability of $20 \mathrm{mg}$ samples of pure CCNF, GO/CCNF-1\%, GO/CCNF-5\%, GO/CCNF-10\%, GO/CCNF-20\%, $\mathrm{GO} / \mathrm{CCNF}-40 \%$, and GO/CCNF-60\% was analyzed from $20{ }^{\circ} \mathrm{C}$ to $600{ }^{\circ} \mathrm{C}$ under nitrogen protection and a heating rate of $10^{\circ} \mathrm{C} / \mathrm{min}$ (STA 449F3, Netzsch Synchronous Thermal Analyzer, Gebrüder, Wuppertal, Germany).

\subsection{Electric-Heating Performance}

The GO/CCNF films were cut to dimensions of $60 \mathrm{~mm} \times 15 \mathrm{~mm}$, and a copper wire, as the electrode, was bonded to each sample using a conductive silver glue. The electrode separation distance was $50 \mathrm{~mm}$, and the films were dried in a vacuum oven at $60{ }^{\circ} \mathrm{C}$ for $1 \mathrm{~h}$. The resistance, current-voltage $(\mathrm{I}-\mathrm{V})$, and electric power-voltage $(\mathrm{P}-\mathrm{V})$ correlations of the GO/CCNF films were investigated using a digital multimeter (F15B+, Fluke Co., Ltd, Everett, WA, USA), a voltage regulator (TDGC2-1000 V, Delixi, Shanghai, China), and an electrical parameter tester (WT310HC, Yokogawa, Tokyo, Japan). The electrical conductivity and electric power of the films were calculated according to the equation $\sigma=L / R S$ ( $\sigma$ : electrical conductivity, $\mathrm{S} / \mathrm{cm}$; $L$ : electrode separation distance, $\mathrm{mm}$; $R$ : resistance, $\Omega$; $S$ : cross-sectional area of the sample, $\left.\mathrm{mm}^{2}\right)$ and $P=I V(P$ : electric power, $W$; I: current, A; $V$ : voltage, $\mathrm{V})$.

The electric-heating performance was investigated using a multi-channel temperature recorder (34972A, Agilent, Rocklin, CA, USA) and an electrical parameter tester (WT310HC, Yokogawa, Tokyo, Japan) to understand the temperature growth and cooling of films at different voltages. The power-on heating time was $500 \mathrm{~s}$, and the power-off cooling time 
was $200 \mathrm{~s}$. Infrared images were obtained using an infrared thermal imager (Ti100, Fluke, Everett, WA, USA).

The electric-heating stability of the GO/CCNF composites with $40 \%$ GO was investigated using a heating and cooling cycle of $45 \mathrm{~V}$ (power-on) to heat for $1000 \mathrm{~s}$, followed by cooling (power-off) for $500 \mathrm{~s}$. The cycling was performed for a duration of $12.5 \mathrm{~h}$. After electrothermal cycling, the films were subjected to Raman spectroscopy (inVia, Renishaw, London, UK) at a wavelength of $633 \mathrm{~nm}$ to analyze the peak changes.

\section{Results}

\subsection{Mechanical Properties and Microstructure}

Figure 2 shows photographs of the GO/CCNF films, SEM images, and partial tensile strength results. The SEM image shows that GO was uniformly distributed inside the electrothermal composite. With an increase in the amount of GO, the contact points between the GO also increase, thereby transforming the insulating film into a conductive composite. This shows that ultrasonic dispersion can effectively mix GO and CCNF, without significant agglomeration of GO, and the original structure was not damaged (Figure 2a-c). According to the stress-strain curves (Figure 2d), the fracture strength and strain of the pure CCNF film were $76.82 \mathrm{MPa}$ and $1.34 \%$, respectively. Conversely, with an increase in the GO content, i.e., in the films with 20, 40, and $60 \mathrm{wt} \% \mathrm{GO}$, the fracture strength and strain decreased to $71.83 \mathrm{MPa}$ and $0.97 \%, 40.09 \mathrm{MPa}$ and $0.42 \%, 30.47 \mathrm{MPa}$ and $0.33 \%$, respectively. Compared with that of the CCNF film, the tensile strength of the 20,40 , and $60 \mathrm{wt} \%$ GO films decreased by $6.50,47.81$, and $60.34 \%$, respectively. Similarly, there was a more significant decrease in the strain of these samples, by $27.61,68.66$, and $75.37 \%$, respectively. These results confirm that the brittleness of the GO/CCNF films increases significantly with an increase in GO. The tensile fracture clearly proves that GO is well-distributed in the composite. However, the mechanical strength of the films is mainly due to the combined effect of the forces between molecules and hydroxyl bonding. When the amount of GO was increased, the contact surface between the GO molecules increased, although the composite retained the mechanical properties of the cellulose nanofiber membrane [27-29]. However, when the GO changed from being wrapped by nanocellulose to being partially connected, and cellulose nanofibers did not form a chemical bond, the mechanical performance deteriorated, and the films exhibited brittle fractures during the stretching process.
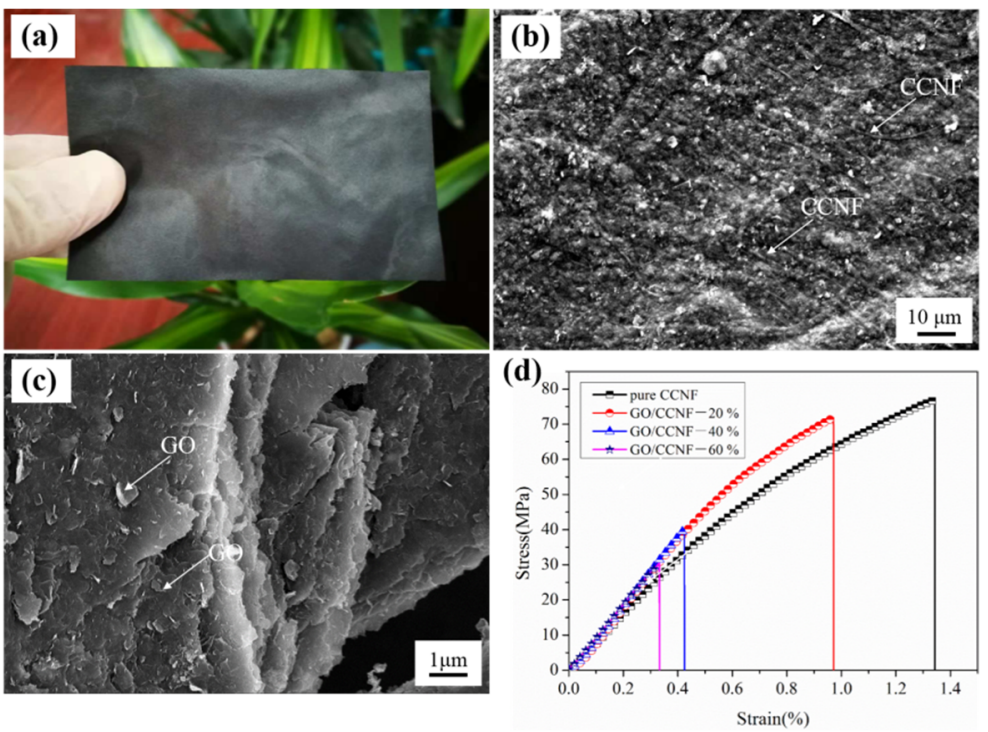

Figure 2. Mechanical properties and microstructure of GO/CCNF films. (a) sample photograph; (b) surface SEM image; (c) tensile section SEM image; (d) stress-strain curves. 


\subsection{Thermal Stability}

Figure 3 shows the TG and DTG curves of the GO/CCNF films. The thermal decomposition of the films can be mainly divided into initial decomposition, main decomposition, and residual decomposition. The first stage $\left(25-250^{\circ} \mathrm{C}\right)$ was that of slow degradation due to moisture volatilization and partial cellulose activation. In this stage, cellulose begins to get activated to form active groups, such as carbonyl and carboxyl groups, and produces $\mathrm{CO}_{2}$ and other gases, with a weight loss of approximately $15 \%$. In the main decomposition stage $\left(250-350{ }^{\circ} \mathrm{C}\right)$, the GO/CCNF films were rapidly pyrolyzed and increased the maximum weight loss temperature. For instance, the maximum degradation temperature was increased by $19^{\circ} \mathrm{C}$ with $60 \mathrm{wt} \% \mathrm{GO}$ compared with that of pure CCNF, which indicates that the heat stability of the films was improved with the addition of GO. In this stage, the weight loss was $64.33,61.85,57.18,52.93,45.71,38.44$, and $26.44 \%$, respectively. The rapid degradation is due to the presence of low-molecular weight solvents and cellulose pyrolysis. Moreover, the DTG curves of the films show that the maximum weight loss temperature gradually increased with GO content, and after heating over $350{ }^{\circ} \mathrm{C}$ is the slow carbon residue process, and the residual mass mainly comprised undecomposed GO and cellulose residue. It is evident that an increase in the GO content improves the thermal stability of the films. However, because of the use of cellulose nanofibers as the matrix, the films should not be exposed to excessively high temperatures, as it may cause thermal degradation during application.
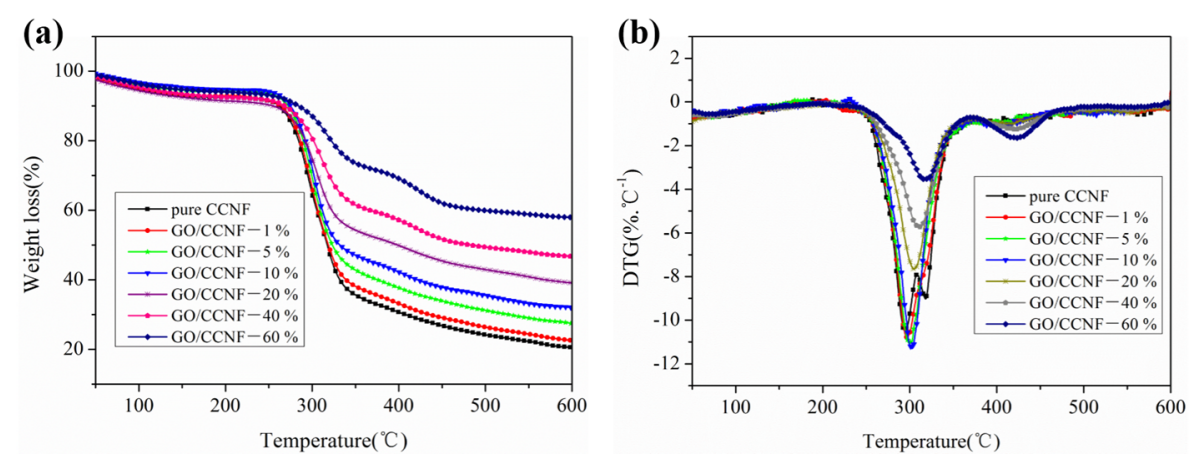

Figure 3. Thermal stability of GO/CCNF films. (a) TG curves; (b) DTG curves.

\subsection{Electrical Conductivity}

Figure 4 shows the electrical conductivities of the GO/CCNF films. We found that GO addition significantly improved the electrical conductivity of the films. The films changed from being insulating composites to conductive composites because the GO promoted the formation of more conductive networks in the films. After the GO content was increased from $20 \mathrm{wt} \%$ to $60 \mathrm{wt} \%$, the electrical conductivity of the films increased rapidly from $0.013 \mathrm{~S} / \mathrm{cm}$ to $2.96 \mathrm{~S} / \mathrm{cm}$. Compared with the $20 \mathrm{wt} \%$ film, there was an increase in the electric conductivity of the 30,40,50, and $60 \mathrm{wt} \%$ films by $0.015 \times 10^{4}, 0.52 \times 10^{4}$, $1.33 \times 10^{4}$, and $2.31 \times 10^{4 \%}$, respectively (Figure $4 \mathrm{a}$ ). This shows that the addition of more than $20 \mathrm{wt} \%$ GO improved the electrical conductivity of the films. The purpose of preparing $\mathrm{GO} / \mathrm{CCNF}$ films is to convert electrical energy into heat energy. Therefore, the correlation between current-voltage and electric power-voltage characteristics was analyzed mainly for the films with $30-60 \mathrm{wt} \% \mathrm{GO}$. The current-voltage of the films is clearly closely related. The values of current through the 30-60 wt\% GO films were $0.005,0.018,0.066$, and $0.095 \mathrm{~A}$ with a load of $23 \mathrm{~V}$ (Figure $4 \mathrm{~b}$ ), indicating that the current through the composites has a greater effect on the voltage. The higher the GO content, the higher is the current. These results are mainly because the current is directly proportional to the electric conductivity under the same applied voltage [30,31]. Furthermore, the electric power is proportional to the square of the voltage under the same resistance conditions. With a load of $23 \mathrm{~V}$, the values of power of the films with $30-60 \mathrm{wt} \%$ GO were $0.11,0.43,1.52$, and $2.21 \mathrm{~W}$ (Figure $4 \mathrm{c}$ ). The power density increased from $122 \mathrm{~W} / \mathrm{m}^{2}$ to 478,1689 , and $2456 \mathrm{~W} / \mathrm{m}^{2}$ 
(Figure 4d). Generally, electrical power is inversely proportional to the resistance; hence, the higher the GO content, the better the power performance of the composite.

(a)
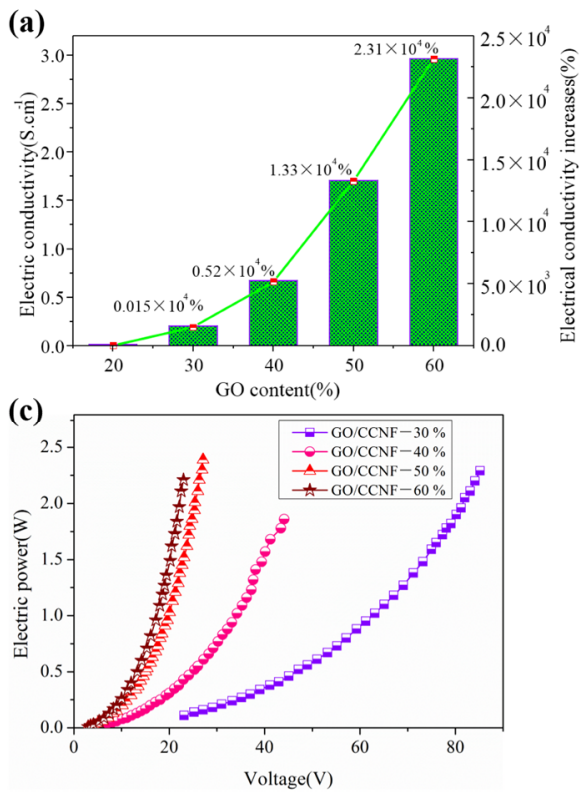
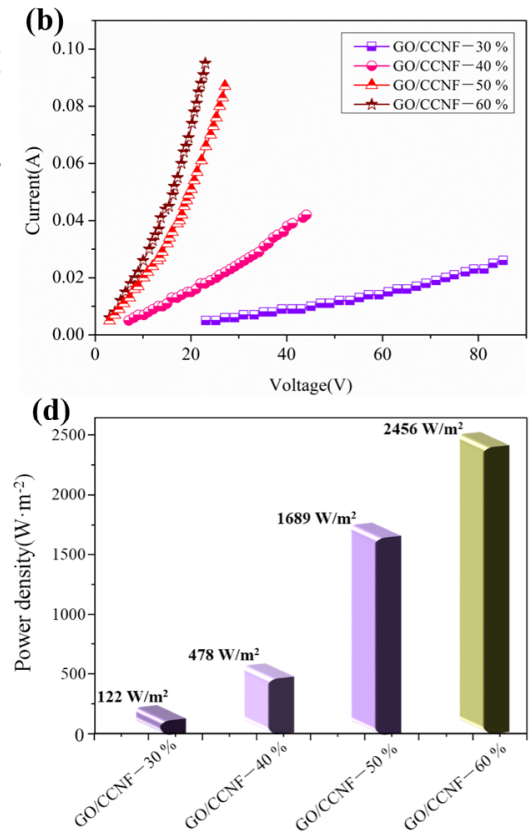

Figure 4. Electrical properties of GO/CCNF films. (a) conductivity; (b) voltage-current curves; (c) power-voltage curves; (d) power density.

\subsection{Electric-Heating Performance}

The time-temperature curves of the GO/CCNF films with 30-60 wt \% GO are shown in Figure 5. The curves are divided into three stages: temperature growth, temperature stabilization, and temperature decline. After applying the load voltage, the temperature of the GO/CCNF films increased rapidly, within $50 \mathrm{~s}$. In this time, the temperature of $\mathrm{GO} / \mathrm{CCNF}-30 \%$ at $25-95 \mathrm{~V}$ reached $94.6,90.3,86.1,82.0,78.0,74.9$, and $69.2 \%$ of the maximum temperature (Figure $5 \mathrm{a}$ ). The temperature stabilization stage can be attained rapidly at a lower voltage. Some of the films continued to generate Joule's heat after a load of $50 \mathrm{~s}$, and the temperature gradually reached equilibrium after a loading voltage of $100 \mathrm{~s}$. The maximum temperatures of the film with $40 \mathrm{wt} \% \mathrm{GO}$ are the range $25.2-103.6^{\circ} \mathrm{C}$ at $15-60 \mathrm{~V}$ (Figure 5b). The electric heating response of the films is more sensitive after GO continued to increase to 50 and $60 \%$; the heating temperature upon heating for $50 \mathrm{~s}$ can reach $72.1-95.1 \%$ and $75.2-95.5 \%$ of the maximum temperature loading of $6-30 \mathrm{~V}$ and 4-22 V, respectively (Figure 5c-d). For example, when the 30, 40, 50, and $60 \mathrm{wt} \%$ films reached the temperature of $91.5^{\circ} \mathrm{C}$, the loading voltages were $95,60,30$, and $22 \mathrm{~V}$, respectively. Hence, to achieve the same heating temperature, a lower voltage is required for samples with a higher GO content. After the voltage application was stopped, the films entered a temperature attenuation stage, and the temperature quickly dropped to the initial temperature. Furthermore, the infrared images of the GO/CCNF films show that the temperature distribution has no obvious high-temperature area and proves that the temperature distribution is relatively uniform, indicating that the GO is uniformly distributed in the cationic cellulose nanofiber matrix. Moreover, electrical safety is one of the key influencing factors in the practical application of electric heating products: an operating voltage below $36 \mathrm{~V}$ meets the requirements of electrical safety, especially in the field of wearable products and indoor heating furniture. The maximum temperatures should typically be in a relatively low temperature range for safety; thus, the GO amount and voltage range can be selected accordingly for different applications [32,33]. 

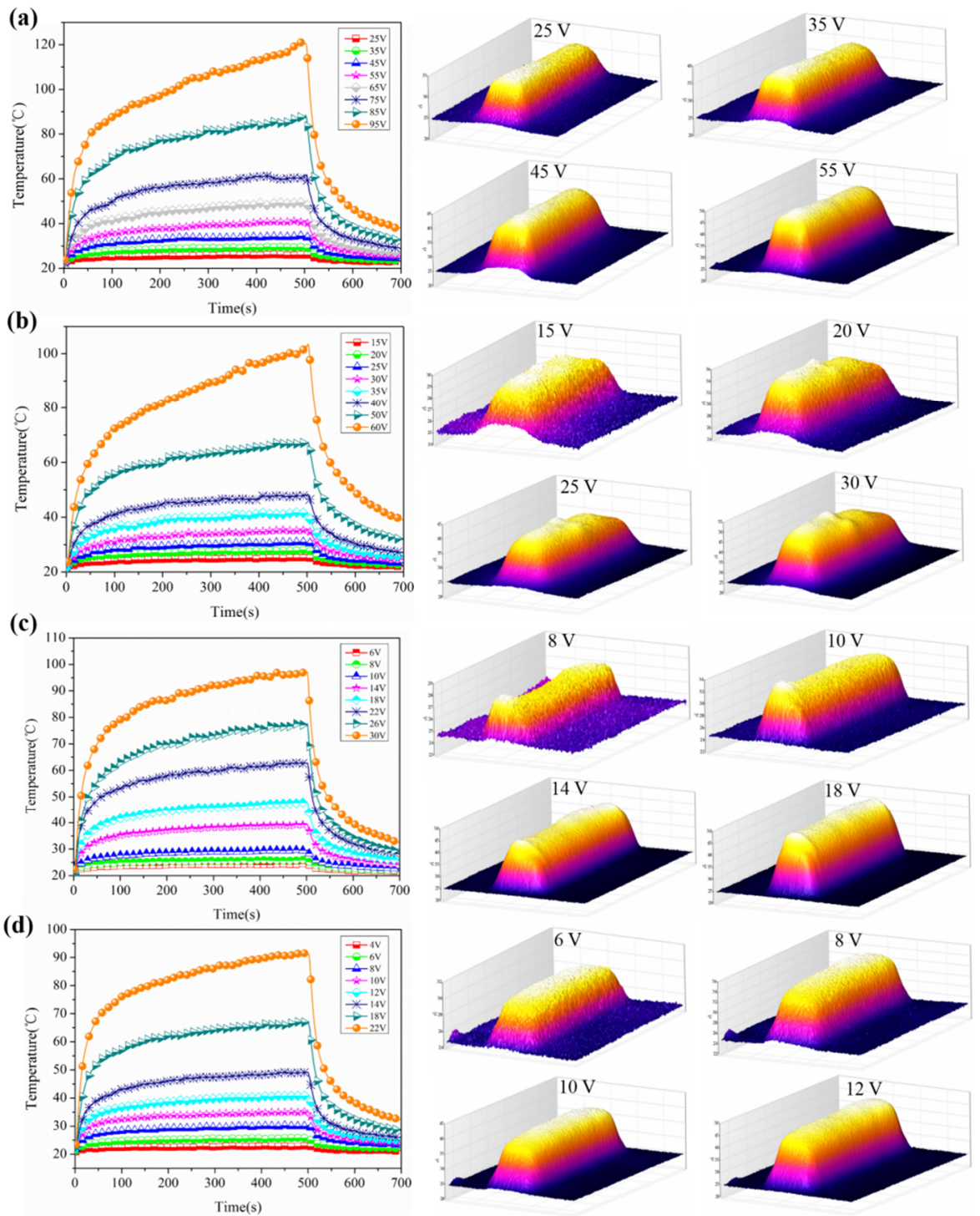

Figure 5. Time-temperature curves and infrared images of GO/CCNF films. (a) GO/CCNF-30\%; (b) GO/CCNF-40\%; (c) GO/CCNF-50\%; (d) GO/CCNF-60\%.

The characteristic growth time constant $\left(\tau_{g}\right)$, decay time constant $\left(\tau_{d}\right)$, and heat transferred by radiation and convection $\left(h_{\mathrm{r}+\mathrm{c}}\right)$ are used to explain the electric heating behavior of electrothermal composites based on the three stages in the time-temperature curves (Figure 5) $[20,30,34]$. In the three temperature regions, $\tau_{g}, \tau_{d}$, and $h_{\mathrm{r}+\mathrm{c}}$ can be described by the following empirical formula:

$$
\begin{aligned}
\left(\frac{T_{t}-T_{0}}{T_{m}-T_{0}}\right) & =1-\exp \left(-\frac{t}{\tau_{g}}\right), \\
\left(\frac{T_{t}-T_{0}}{T_{m}-T_{0}}\right) & =\exp \left(-\frac{t}{\tau_{d}}\right), \\
h_{r+c} & =\frac{I_{c} V_{0}}{T_{m}-T_{0}}
\end{aligned}
$$

where $T_{0}$ is the initial temperature, $T m$ is the maximum temperature, $T t$ is an arbitrary temperature at time $t, I c$ is the steady-state current, and $V_{0}$ is the initial applied voltage. Figure 6 shows the electric heating parameters of GO/CCNF films as derived from the equations. The film exhibited a fast temperature response performance for smaller values 
of $\tau_{g}$ and $\tau_{d}$, indicating that the shorter the time taken for the electric heating composite to heat from the starting temperature to the maximum temperature, lesser is the time required to cool down from the maximum temperature. The $\tau_{g}$ range was $41.27-56.26 \mathrm{~s}$ and the average value with $30-60 \mathrm{wt} \% \mathrm{GO}$ addition was $48.67 \mathrm{~s}$. This further proves that the fastest temperature increase time of the GO/CCNF film was approximately $50 \mathrm{~s}$; the higher the amount of GO added, the more beneficial the rapid electric-heating response. The $\tau_{d}$ value of films varied with time in the range of 34.47-47.13 s, indicating that the maximum temperature drops to the initial temperature in a short time after stopping voltage, which is beneficial to the heating-cooling cycle response. Furthermore, the $h_{r+c}$ value is a key indicator that is characteristic of the conversion efficiency of an electric heating film in converting electrical energy to thermal energy. The lower the electric power consumed by the film with every increase of $1^{\circ} \mathrm{C}$, the higher is the electric-to-radiant power transfer efficiency. The average $h_{r+c}$ value of GO/CCNF films with $30 \mathrm{wt} \% \mathrm{GO}$ is $36.49 \mathrm{~mW} /{ }^{\circ} \mathrm{C}$ under a load voltage in the range of $25-95 \mathrm{~V}$. When the GO increases to $60 \mathrm{wt} \%$, its average $h_{r+c}$ value is $21.62 \mathrm{~mW} /{ }^{\circ} \mathrm{C}$ using $4-22 \mathrm{~V}$. The $h_{r+c}$ is considerably improved with an increase in $\mathrm{GO}$ and requires a lower voltage, which proves that the composite prepared in this study can be used to produce low-voltage and high-efficiency electric-heating products.

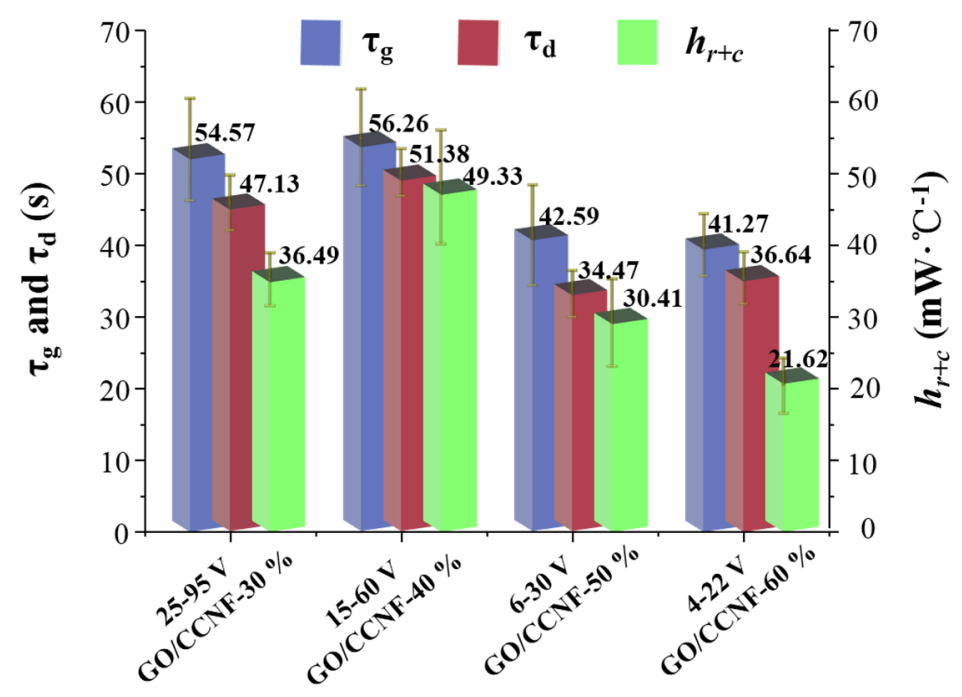

Figure 6. Electric-heating parameters of GO/CCNF films.

\subsection{Electric-Heating Cycle Performance}

To analyze the electric-heating cycle performance of the GO/CCNF films, the cycle performance of GO/CCNF-40\% was tested for $12.5 \mathrm{~h}$ for heating and cooling cycles at a load voltage of $45 \mathrm{~V}$. The electric-heating stability of the film did not exhibit an attenuation phenomenon. However, there is a certain difference in the maximum temperature of each cycle, with maximum temperatures in the range of $45.76-49.97^{\circ} \mathrm{C}$. Furthermore, the maximum temperature difference of the heating film is $4.21^{\circ} \mathrm{C}$ during the $12.5 \mathrm{~h}$ heating and cooling cycle (Figure 7a). This is probably because of the environmental change in the heat radiation exchange and voltage deviation of the test system, but the electric-toradiant power transfer efficiency of the composite was not affected. The results show that the film has a stable electric-heating cycle performance and exhibits good flexibility after the electric-heating cycle. In addition, Raman spectroscopy results show that the D-peak and G-peak before the electric-heating cycle were 1328.50 and $1594.81 \mathrm{~cm}^{-1}$. In contrast, the D-peak and G-peak after electric heating cycle were 1331.04 and $1597.80 \mathrm{~cm}^{-1}$ (Figure $7 \mathrm{~b}$ ). It is known that the D-peak represents the defects and disordered structure in the composite, and the intensity of the G-peak is determined by the degree of structural disorder. Furthermore, the ratio of the two characteristic peaks, $\mathrm{I}_{\mathrm{D}} / \mathrm{I}_{\mathrm{G}}$, represents the defect density of the composite. The $\mathrm{I}_{\mathrm{D}} / \mathrm{I}_{\mathrm{G}}$ of the $\mathrm{GO} / \mathrm{CCNF}$ film was 0.83 before the electric- 
heating cycle and after cycling; that is, the degree of disorder of the carbon atoms in the film and the size of the existing defects did not change. Moreover, the oxygen-containing functional groups and the order of the $\mathrm{sp}^{2}$ type carbon structure were not affected after the electric heating cycle, enabling the electric heating film to maintain a stable electric-heating cycle performance and flexibility (Figure 7c) [31].
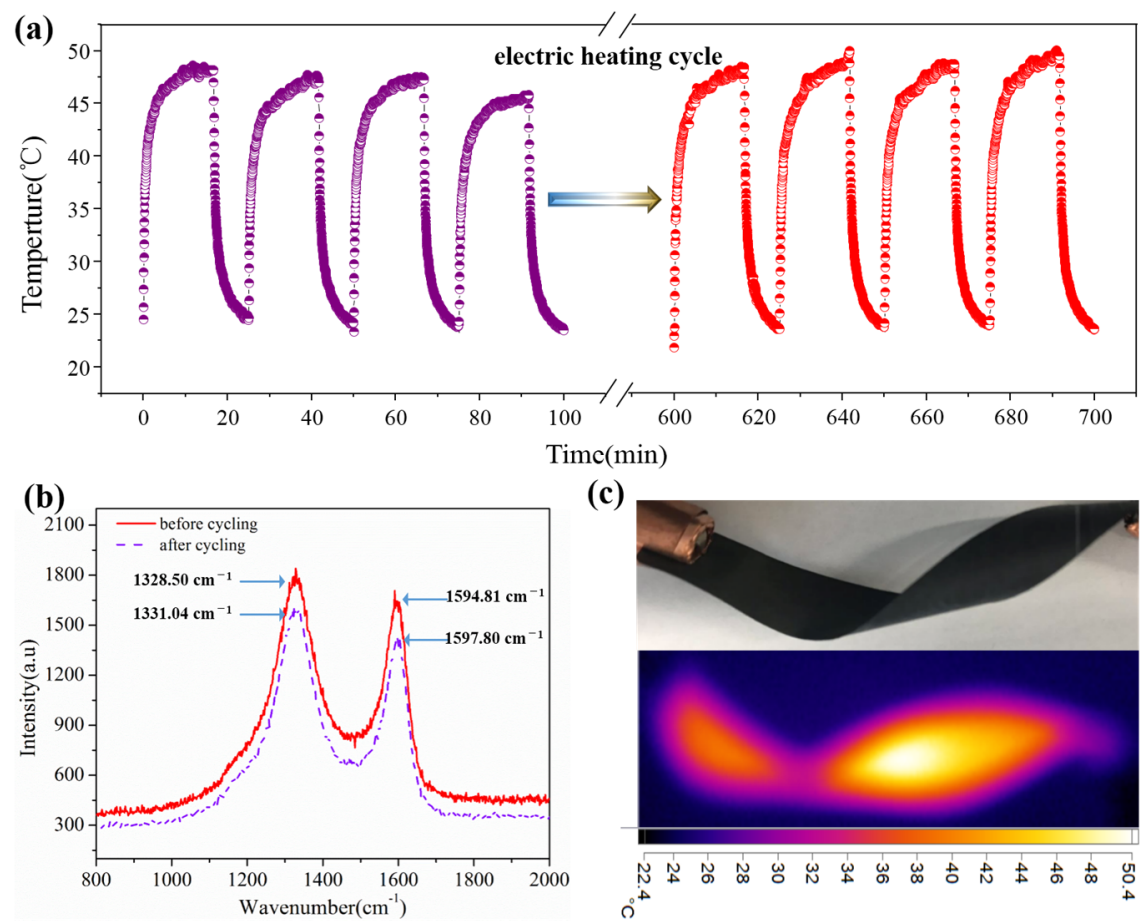

Figure 7. Electric-heating cycle performance of GO/CCNF film. (a) heating and cooling cycle; (b) Raman spectra; (c) flexibility.

\section{Conclusions}

GO/CCNF films were successfully prepared, and their structural morphology, tensile strength, electrical conductivity, electric-heating performance, and cycle stability were investigated. GO was found to be uniformly distributed in the films, and the amount of GO affected their tensile properties and conductive network. The films were transformed from an insulating material to a $2.96 \mathrm{~S} / \mathrm{cm}$ conductive composite. The power density of the films increased from 122 to $2456 \mathrm{~W} / \mathrm{m}^{2}$ as the GO content increased from 20 to $60 \mathrm{wt} \%$. The heating temperature of the GO/CCNF films increased rapidly, within $50 \mathrm{~s}$, and the temperature gradually reached equilibrium after $100 \mathrm{~s}$. The average temperature growth coefficient was $48.67 \mathrm{~s}$, which indicates that the GO/CCNF film has sensitive electric heating response characteristics. The electric-to-radiant power transfer efficiencies of films with different contents of GO/CCNF were in the range of $21.62-36.49 \mathrm{~mW} /{ }^{\circ} \mathrm{C}$. In addition, after a $12.5 \mathrm{~h}$ electric-heating cycle, it was found that the film demonstrated a stable electric-heating performance and flexibility, which can be used to fabricate low-voltage and high-efficiency electric-heating products.

Author Contributions: Conceptualization, S.L.; methodology, S.L.; software, S.L. and H.W.; validation, S.L. and X.T.; formal analysis, S.L. and X.T.; investigation, H.W. and X.T.; resources, S.L.; data curation, S.L. and H.W.; writing-original draft preparation, H.W.; writing-review and editing, S.L. and X.T.; visualization, S.L. and H.W.; supervision, S.L.; project administration, S.L.; funding acquisition, S.L. All authors have read and agreed to the published version of the manuscript.

Funding: This research was funded by the National Natural Science Foundation of China (Project No.32071705) and the Special Fund of the Chinese Central Government for Basic Scientific Research Operations in Commonwealth Research Institutes (Project No.CAFYBB2016MB001). 
Data Availability Statement: The data presented in this study are available on request from the corresponding author.

Conflicts of Interest: The authors declare no conflict of interest.

\section{References}

1. Lu, H.B.; Zhu, S.P.; Yang, Y.H.; Huang, W.M.; Leng, J.S.; Du, S.Y. surface grafting of carbon fibers with artificial sil-vernanoparticledecorated graphene oxide for high-speed electrical actuation of shape-memory polymers. J. Appl. Polym. Sci. 2015, $132,41673$.

2. Loeblein, M.; Bolker, A.; Tsang, S.H.; Atar, N.; Saguy, C.U.; Verker, R.; Gouzman, I.; Grossman, E.; Teo, E.H.T. Flexible electronics: 3D graphene-infused polyimide with enhanced electrothermal performance for long-term flexible space applications. Small $\mathbf{2 0 1 5}$ 48, 6425-6434. [CrossRef]

3. Montes, S.; Carrasco, P.M.; Ruiz, V.; Cabanero, G.; Grande, H.J.; Labidi, J.; Odriozola, I. Synergistic reinforcement of poly(vinyl alcohol) nanocomposites with cellulose nanocrystal-stabilized graphene. Compos. Sci. Technol. 2015, 117, 26-31. [CrossRef]

4. Janas, D.; Koziol, K.K. A review of production methods of carbon nanotube and graphene thin films for electrothermal applications. Nanoscale 2014, 6, 3037-3045. [CrossRef] [PubMed]

5. Wang, R.; Xu, Z.; Zhuang, J.; Liu, Z.; Peng, L.; Liu, Y.; Gao, W.; Gao, C. Highly Stretchable Graphene Fibers with Ultrafast Electrothermal Response for Low-Voltage Wearable Heaters. Adv. Electron. Mater. 2017, 3, 1600425. [CrossRef]

6. Xiao, Z.; Sheng, C.; Xia, Y.; Yu, X.; Liang, C.; Huang, H.; Gan, Y.; Zhang, J.; Zhang, W. Electrical heating behavior of flexible thermoplastic polyurethane/Super-P nanoparticle composite films for advanced wearable heaters. J. Ind. Eng. Chem. 2019, 71, 293-300. [CrossRef]

7. Tian, M.; Hao, Y.; Qu, L.; Zhu, S.; Zhang, X.; Chen, S. Enhanced electrothermal efficiency of flexible graphene fabric Joule heaters with the aid of graphene oxide. Mater. Lett. 2019, 234, 101-104. [CrossRef]

8. Huang, K.; Liu, J.; Tan, L.; Zuo, J.; Fu, L. Ultrahigh Temperature Graphene Molecular Heater. Adv. Mater. Interfaces 2018, 5, 1701299. [CrossRef]

9. Sun, H.; Chen, D.; Ye, C.; Li, X.; Dai, D.; Yuan, Q.; Chee, K.W.; Zhao, P.; Jiang, N.; Lin, C.-T. Large-area self-assembled reduced graphene oxide/electrochemically exfoliated graphene hybrid films for transparent electrothermal heaters. Appl. Surf. Sci. 2018, 435, 809-814. [CrossRef]

10. Zhang, X.; Li, D.; Liu, K.; Tong, J.; Yi, X.; XuFeng, Z.; Dihui, L.; Kejian, L.; JianFeng, T.; Xiaosu, Y. Flexible graphene-coated carbon fiber veil/polydimethylsiloxane mats as electrothermal materials with rapid responsiveness. Int. J. Lightweight Mater. Manuf. 2019, 2, 241-249. [CrossRef]

11. Kalita, G.; Wakita, K.; Umeno, M. Low temperature growth of graphene film by microwave assisted surface wave plasma CVD for transparent electrode application. RSC Adv. 2012, 2, 2815-2820. [CrossRef]

12. Lee, B.-J.; Jeong, G.-H. Fabrication of defrost films using graphenes grown by chemical vapor deposition. Curr. Appl. Phys. 2012, 12, S113-S117. [CrossRef]

13. Li, C.; Xu, Y.T.; Zhao, B.; Li, C.; Wong, C.P. Flexible grapheme electrothermal films made from electrochemically exfoliated graphite. J. Mater. Sci. 2016, 51, 1043-1051. [CrossRef]

14. Liu, Z.; Xu, Z.; Xia, Z.; Hu, X.; Kou, L.; Peng, L.; Wei, Y.; Gao, C. Wet-Spun Continuous Graphene Films. Chem. Mater. 2014, 26, 6786-6795. [CrossRef]

15. Sui, D.; Huang, Y.; Huang, L.; Liang, J.J.; Ma, Y.F.; Chen, Y.S. Flexible and transparent electrothermal film heaters based on graphene mater. Small 2011, 22, 3186-3192. [CrossRef]

16. Teodoro, K.B.; Migliorini, F.L.; Facure, M.H.; Correa, D.S. Conductive electrospun nanofibers containing cellulose nanowhiskers and reduced graphene oxide for the electrochemical detection of mercury (II). Carbohydr. Polym. 2019, 207, 747-754. [CrossRef]

17. Montes, S.; Etxeberria, A.; Mocholi, V.; Rekondo, A.; Grande, H.; Labidi, J. Effect of combining cellulose nanocrystals and graphene nanoplatelets on the properties of poly(lactic acid) based films. Express Polym. Lett. 2018, 12, 543-555. [CrossRef]

18. Chen, G.Y.; Chen, T.; Hou, K.; Ma, W.J.; Tebyetekerwa, M.; Cheng, Y.H.; Weng, W.; Zhu, M.F. Robust, hydrophilic graphene/cellulose nanocrystal fiber-based electrode with high capacitive performance and conductivity. Carbon 2018, 127, 218-227. [CrossRef]

19. Liu, D.; Dong, Y.; Liu, Y.; Ma, N.; Sui, G. Cellulose Nanowhisker (CNW)/Graphene Nanoplatelet (GN) Composite Films with Simultaneously Enhanced Thermal, Electrical and Mechanical Properties. Front. Mater. 2019, 6, 235. [CrossRef]

20. Lee, T.W.; Jeong, Y.G. Regenerated cellulose/multiwalled carbon nanotube composite films with efficient electric heating performance. Carbohydr. Polym. 2015, 133, 456-463. [CrossRef]

21. Lee, T.W.; Lee, S.E.; Jeong, Y.G. Carbon nanotube/cellulose papers with high performance in electric heating and electro-magnetic interference shielding. Compos. Sci. Technol. 2016, 131, 77-87. [CrossRef]

22. Andres, B.; Dahlström, C.; Blomquist, N.; Norgren, M.; Olin, H. Cellulose binders for electric double-layer capacitor electrodes: The influence of cellulose quality on electrical properties. Mater. Des. 2018, 141, 342-349. [CrossRef]

23. Trache, D.; Thakur, V.K.; Boukherroub, R. Cellulose Nanocrystals/Graphene Hybrids: A Promising New Class of Materials for Advanced Applications. Nanomaterials 2020, 10, 1523. [CrossRef] [PubMed]

24. Li, K.; Jin, S.; Han, Y.; Li, J.; Chen, H. Improvement in Functional Properties of Soy Protein Isolate-Based Film by Cellulose Nanocrystal-Graphene Artificial Nacre Nanocomposite. Polymers 2017, 9, 321. [CrossRef] [PubMed] 
25. Xiong, R.; Hu, K.; Grant, A.M.; Ma, R.; Xu, W.; Lu, C.; Zhang, X.; Tsukruk, V.V. Ultrarobust Transparent Cellulose NanocrystalGraphene Membranes with High Electrical Conductivity. Adv. Mater. 2015, 28, 1501-1509. [CrossRef] [PubMed]

26. Zhang, K.; Ketterle, L.; Järvinen, T.; Lorite, G.S.; Hong, S.; Liimatainen, H. Self-assembly of graphene oxide and cellulose nanocrystals into continuous filament via interfacial nanoparticle complexation. Mater. Des. 2020, 193, 108791. [CrossRef]

27. Cui, S.; Wei, P.; Li, L. Preparation of poly (propylene carbonate)/graphite nanoplates-spherical nanocrystal cellulose composite with improved glass transition temperature and electrical conductivity. Compos. Sci. Technol. 2018, 168, 63-73. [CrossRef]

28. Kabiri, R.; Namazi, H. Nanocrystalline cellulose acetate (NCCA)/graphene oxide (GO) nanocomposites with enhanced mechanical properties and barrier against water vapor. Cellulose 2014, 21, 3527-3539. [CrossRef]

29. Yang, F.; Wu, Y.; Zhang, S.; Zhang, H.; Zhao, S.; Zhang, J.; Fei, B. Mechanical and Thermal Properties of Waterborne Polyurethane Coating Modified through One-Step Cellulose Nanocrystals/Graphene Materials Sols Method. Coatings 2020, 10, 40. [CrossRef]

30. Jeon, G.W.; Jeong, Y.G. Electric heating films based on m-aramid nanocomposites containing hybrid fillers of graphene and carbon nanotube. J. Mater. Sci. 2013, 48, 4041-4049. [CrossRef]

31. Tian, S.; He, P.; Chen, L.; Wang, H.; Ding, G.; Xie, X. Electrochemical Fabrication of High Quality Graphene in Mixed Electrolyte for Ultrafast Electrothermal Heater. Chem. Mater. 2017, 29, 6214-6219. [CrossRef]

32. Zhang, T.Y.; Zhao, H.M.; Yang, Z.; Wang, Q.; Wang, D.Y.; Deng, N.Q.; Yang, Y.; Ren, T.L. Improved electrothermal performance of custom-shaped micro heater based on anisotropic laser-reduced graphene oxide. Appl. Phys. Lett. 2016, 109, 151905. [CrossRef]

33. Zhao, H.; Tian, M.; Hao, Y.; Qu, L.; Zhu, S.; Chen, S. Fast and facile graphene oxide grafting on hydrophobic polyamide fabric via electrophoretic deposition route. J. Mater. Sci. 2018, 53, 9504-9520. [CrossRef]

34. Farid, E.T. Joule heating treatments of conductive butyl rubber/ceramic superconductor composites: A new way for improving the stability and reproducibility. Eur. Polym. J. 2001, 3, 565-574. 